\title{
Dynamic Analysis of Sandwich Beam with Viscoelastic Core Under Moving Load
}

\author{
Sabiiha TEKILI*, Youcef KHADRI**, Yacine KARMI*** \\ *Université Badji Mokhtar BP12- Annaba, Laboratoire LMI, Algérie, E-mail: tekili.sabah@gmail.com \\ **Université Badji Mokhtar BP12-Annaba, Laboratoire LMI, Algérie, E-mail: khadri152000@yahoo.fr \\ ***Université Badji Mokhtar BP12-Annaba, Département de Mécanique, Algérie, E-mail: karmi.yacine92@gmail.com \\ cross ${ }^{\text {ref }}$ http://dx.doi.org/10.5755/j01.mech.26.4.23956
}

\section{Introduction}

The knowledge of dynamic characteristics is very necessary and useful in the design and rehabilitation of structures equipped with viscoelastic materials, because due to their specific mechanical properties, viscoelastic materials contribute to the attenuation of structural vibrations. Structures by viscoelastic materials are often used in various dynamic loading conditions and in several areas during the last decades. Therefore, the viscoelastic materials development in the structures requires the implementation approaches characterizing their vibration behavior. Many research works have studied the structures vibrations under moving dynamic loads. This type of load generally causes vibrations that can extinguish the performance of the structure. These studied are focused on the impact of different dynamic parameters [1-4]. Based on the Bernoulli beam theory, a three-dimensional finite element model was proposed by Kiral et al. [5] to characterize the dynamic response of a clamped-clamped beam under dynamic load. Fuh-Gwo Y. [6] have proposed a vibration analysis model for multilayer laminated composite beams under moving load. Kahya V. [7] employed the Timoshenko theory to take into account the shear effect in each layer of composite. Sarvestan V. et al. [8] employed a quadratic equation for the moving load in order to determine the vibratory responses of the cracked Timoshenko beam under moving load. Nevertheless, the viscoelastic materials can be used as damping materials because of their specific properties. Generally, few researchers interested in linear and nonlinear viscoelastic sandwich vibrations under moving load. Irazu L. et al. [9] investigate the effect of geometric parameters on the dynamic behavior of thin sandwich structures with viscoelastic core. Billasse et al. [10] presents a numerical approach using finite element bases solution for viscoelastic sandwich vibrations. In this work, the dynamic responses of viscoelastic sandwich beams under moving load were obtained. The Hamilton principle is applied to obtain the motion equation while the finite element method is applied for the problem discretization. Different configurations of the sandwich beams and with various loss factor are considered in this study.

\section{Mathematical model}

The viscoelastic sandwich beam studied in this work is composed of a viscoelastic layer placed between two elastic layers constituting the sandwich skins; the beam is the length $L$ and the width $b$ (Fig.1). The displacement and linear strain fields of the ith face layer are given by [10]:

$$
\begin{aligned}
& U_{i}(x, z, t)=u_{i}(x, t)-\left(z-z_{i}\right) w^{\prime} \\
& W_{i}(x, z, t)=w(x, t) \quad i=1,3 \\
& \varepsilon_{i}(x, z, t)=u_{i}^{\prime}(x, t)-\left(z-z_{i}\right) w^{\prime \prime}
\end{aligned},
$$

where: $U_{i}$ and $W_{i}$ are the axial displacement and the transverse displacement in the face layers for any $(x)$ location, respectively. $u_{i}$ represents the axial displacement at the centroid of the $i$ th layer and $w$ is the common transverse displacement. The subscripts $i=1.3$ refer to the upper and lower layers respectively.

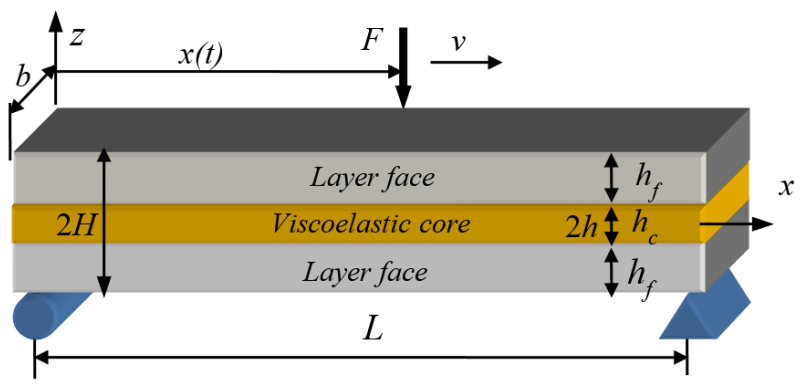

Fig. 1 Geometry of a viscoelastic sandwich beam $z_{1}=\frac{1}{2}\left(h_{f}+h_{c}\right)=-z_{3}$, corresponding to the middle planes ordinates of the upper and lower layers respectively. $h_{f}$ and $h_{c}$ are thickness of the face layers and of the viscoelastic core, respectively. The notations $(g$ ', $g$ ") stand for the spatial derivatives $\left(\partial g / \partial x, \partial^{2} g / \partial x^{2}\right)$. Taking into account the shear in the viscoelastic layer, displacement and linear strain fields of the core layer are given by:

$$
\begin{aligned}
& U_{2}(x, z, t)=u(x, t)-z \beta(x, t) \\
& W_{2}(x, z, t)=w(x, t) \\
& \varepsilon_{n 2}(x, z, t)=u^{\prime}(x, t)+z \beta^{\prime}, \\
& \varepsilon_{s 2}(x, z, t)=\beta(x, t)+w^{\prime}
\end{aligned},
$$

where: $U_{2}$ and $W_{2}$ are the axial displacement and the transverse displacement in the core layer for any $(x)$ location, respectively. $\beta$ and $u$ corresponds to the displacement and the rotation normal of the viscoelastic layer's mid-plane, respectively. $\varepsilon_{\mathrm{s} 2}$ is the shear strain of viscoelastic layer and $\varepsilon_{n 2}$ the normal deformation. The subscript $i=2$ refers to the core layer. The equations describing the relationship between the viscoelastic $(u, \beta)$ and face layers $\left(u_{1}, u_{3}\right)$ are given by [10]:

$$
u_{1}=u+\frac{1}{2}\left(h_{c} \beta-h_{f} w^{\prime}\right), u_{3}=u-\frac{1}{2}\left(h_{c} \beta-h_{f} w^{\prime}\right)
$$


The formulation of the motion equation of the viscoelastic sandwich beam is described by the Hamilton principle. The strain energy of the beam can be expressed as follows [11]:

$$
V=\sum_{i=1}^{3}\left[\frac{1}{2} \int_{v}\left(\sigma_{i j} \varepsilon_{i j}\right) d v\right],
$$

where: $\sigma_{i j}$ and $\varepsilon_{i j}$ are stress and strain, respectively. The kinetic energy of the beam is:

$$
T=\sum_{i=1}^{3}\left[\frac{1}{2} \int_{v}\left(\rho_{i} \dot{u}_{i} \dot{u}_{i}+\rho_{i} \dot{w}_{i} \dot{w}_{i}\right) d v\right],
$$

in which $\rho_{i}$ is the density of the ith layer and the notation $\dot{g}$ represents the first partial derivative of time $(\partial g / \partial t)$. The virtual work of the moving load can be expressed as follows:

$$
W=\sum_{i=1}^{3}\left[\int_{v} F(x, t) w d v\right]
$$

The moving load $F(x, t)$ is simply given by:

$$
F(x, t)=F_{0} \delta(x-s(t)),
$$

where: $\delta($.$) is the Dirac-Delta function, F_{0}$ refers to the constant force and $s(t)=v t$ is the function describing the moving of the load $F_{0}$ at time $t$, with $v$ is the speed of the moving load. By using the Hamilton's principle and Eqs. (4), (5), and (6), and with the terms of axial inertia and the axial excitation force neglected, the bending motion equation can be obtained [10]:

$$
\begin{aligned}
& \int_{0}^{L}\left\{w^{\prime} \delta w^{\prime}+M_{\beta} \delta \beta^{\prime}+M_{w} \delta w^{\prime \prime}+T\left(\delta w^{\prime}+\delta \beta\right)\right\} d x= \\
& =\int_{0}^{L} F_{0} \delta(x-s(t)) \delta w d x-\left(2 \rho_{f} S_{f}+\rho_{c} S_{c}\right) \int_{0}^{L} \ddot{w} \delta w d x \\
& M_{\beta}=I_{c} Y * \dot{\beta}^{\prime}+\frac{E_{f} S_{f} h_{c}}{2}\left(h_{c} \beta^{\prime}-h_{f} w^{\prime \prime}\right) \\
& M_{w}=E_{f}\left(2 I_{f}+\frac{S_{f} h_{f}^{2}}{2}\right) w^{\prime \prime}-\frac{E_{f} S_{f} h_{c} h_{f}}{2} \beta^{\prime}, \\
& T=\frac{S_{c}}{2\left(1+v_{c}\right)} Y *\left(\dot{\beta}+\dot{w}^{\prime}\right)
\end{aligned}
$$

where: $T$ is shear force and $M_{\beta}$ and $M_{w}$ are bending moment. $\rho_{f}$ and $\rho_{c}$ are mass density of the face layers and viscoelastic core, respectively. $S_{f}$ and $S_{c}$ are cross-section area of the face layers and viscoelastic core, respectively. $Y$ and $v_{c}$ are the relaxation function and the Poisson ratio of the viscoelastic material, respectively. $I_{f}$ and $I_{c}$ are second moment of the face layers and viscoelastic core, respectively. The notation $\ddot{g}$ stand for temporal derivative $\left(\partial^{2} g / \partial t^{2}\right)$. No analytical solution of Eq. (8), this equation is a nonlinear differential equation; only approximated solutions will be investigated. In this paper, the approximate solution of the linear bending equation (8) is obtained by coupling the one-mode Galerkin approximation with the harmonic balance method [10]:

$$
w(x, t)=W(x) e^{i \omega t}, \quad \beta(x, t)=B(x) e^{i \omega t} .
$$

\section{Finite element discretization}

The finite element method will be used for the numerical discretization of the Eq. (8). An element with two nodes is used in this study, at each node there degrees of freedom (the transverse displacement $w$, the rotation of the normal of the central layer $\beta$ and the rotation $w^{\prime}$ ) as shown in the Fig. 2.

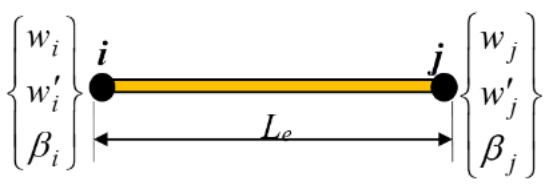

Fig. 2 Two-node sandwich beam element

The displacement field expression as a function of the nodal displacements make:

$$
\left\{q^{e}\right\}=\left\{\begin{array}{llllll}
w_{i} & w_{i}^{\prime} & \beta_{i} & w_{j} & w_{j}^{\prime} & \beta_{j}
\end{array}\right\}^{T},
$$

Using classical polynomial shape functions [12], the element displacement field vector is written as:

$$
\left\{\begin{array}{l}
w \\
\beta
\end{array}\right\}=\left[\begin{array}{l}
N_{w} \\
N_{\beta}
\end{array}\right]\left\{q^{e}\right\}
$$

where: $\left[N_{w}\right]$ and $\left[N_{\beta}\right]$ are the interpolation functions matrices given by [12]:

$$
\begin{aligned}
& {\left[N_{w}\right]=\left[\begin{array}{llllll}
N_{w 1} & N_{w 2} & 0 & N_{w 3} & N_{w 4} & 0
\end{array}\right],} \\
& {\left[\begin{array}{l}
N_{\beta}
\end{array}\right]=\left[\begin{array}{llllll}
0 & 0 & N_{\beta 5} & 0 & 0 & N_{\beta 6}
\end{array}\right]}
\end{aligned}
$$

with $N_{\mathrm{w} 1}=1+2 \frac{x^{3}}{L_{e}^{3}}-3 \frac{x^{2}}{L_{e}^{2}}, N_{\mathrm{w} 2}=\left(\frac{x^{3}}{L_{e}^{3}}-2 \frac{x^{2}}{L_{e}^{2}}+\frac{x}{L_{e}}\right) L_{e}$,

$N_{\mathrm{w} 3}=-2 \frac{x^{3}}{L_{e}^{3}}+3 \frac{x^{2}}{L_{e}^{2}}, N_{4}=\left(\frac{x^{3}}{L_{e}^{3}}-\frac{x^{2}}{L_{e}^{2}}\right) L_{e}$,

$N_{\beta 5}=\left(1-\frac{x}{L_{e}}\right), N_{\beta 6}=\left(\frac{x}{L_{e}}\right)$, for $x \in\left[\begin{array}{ll}0 & L_{e}\end{array}\right]$.

Inserting Eqs. (9)- (12), into Eq. (8), one gets the following frequency-amplitude equation:

$$
\left(\left[K^{e}(\omega)\right]-\omega^{2}\left[M^{e}\right]\right)\left\{q^{e}\right\}=\left\{F^{e}\right\},
$$

where: $\left[M^{\mathrm{e}}\right]$ and $\left[K^{\mathrm{e}}\right]$ are element mass and stiffness matrices, respectively, given by [10]:

$$
\begin{aligned}
& {\left[K^{e}\right]=\frac{1}{2}\left\{\left(2 I_{c} E_{c}(\omega)+E_{f} I_{f} h_{c}^{2}\right)\left[k_{1}^{e}\right]-E_{f} S_{f} h_{f} h_{c}\left[k_{2}^{e}\right]\right\}+} \\
& +\frac{1}{2}\left\{\left(E_{f}\left(4 I_{f}+S_{f} h_{f}^{2}\right)\left[k_{3}^{e}\right]+\frac{S_{c} E_{c}(\omega)}{\left(1+v_{c}\right)}\left[k_{4}\right]\right\},\right.
\end{aligned}
$$

where: $\left[m^{e}\right]=\int_{0}^{L_{e}}\left[N_{w}\right]\left[N_{w}\right] d x ; \quad\left[k_{1}^{e}\right]=\int_{0}^{L_{e}}\left[N_{\beta}^{\prime}\right]\left[N_{\beta}^{\prime}\right] d x ;$ $\left[k_{2}^{e}\right]=\int_{0}^{L_{e}}\left({ }^{T}\left[N_{\beta}^{\prime}\right]\left[N_{w}^{\prime \prime}\right]+{ }^{T}\left[N_{w}^{\prime \prime}\right]\left[N_{\beta}^{\prime}\right]\right) d x ;\left[k_{3}^{e}\right]=\int_{0}^{L_{e}}\left[N_{w}^{\prime \prime}\right]\left[N_{w}^{\prime \prime}\right] d x$ 


$$
\left[k_{4}^{e}\right]=\int_{0}^{L_{e}}\left\{\begin{array}{l}
T\left[N_{w}^{\prime}\right]\left[N_{w}^{\prime}\right]+{ }^{T}\left[N_{\beta}\right]\left[N_{w}^{\prime}\right]+{ }^{T}\left[N_{w}^{\prime}\right]\left[N_{\beta}\right]+ \\
+{ }^{T}\left[N_{\beta}\right]\left[N_{\beta}\right]
\end{array}\right\} d x .
$$

The $\left\{F^{\mathrm{e}}\right\}$ is element force vector:

$$
\left\{F^{e}\right\}=F_{0} \int_{0}^{L^{e}} \delta(x-v t)^{T}\left[N_{w}\right] d x .
$$

These matrices are assembled to get the overall complex nonlinear eigenvalue problem:

$$
\left([K(\omega)]-\omega^{2}[M]\right)\{Q\}=0,
$$

where: $[K]$ and $[M]$ are the assembled mass and stiffness matrices, respectively and $\{Q\}$ is the vibration amplitude. The Eq. (16) can be solved by different methods of the eigenvalue problem as described in [13]. The amplitude equation (16) leads to an approximate value of the complex eigenfrequency that can written in the following classical form:

$$
\omega^{2}=\frac{K}{M}=\Omega^{2}(1+i \eta)
$$

where: $\eta$ is the structure loss factor and $\Omega$ is the structure linear frequency. The stiffness matrix $K$ is complex with a real $K^{R}$ and an imaginary $K^{I}$ parts. The viscoelastic frequency and the loss factor of the viscoelastic structure are related to the real and imaginary parts of the linear stiffness by the following relationship:

$$
K=K^{R}+i K^{I} .
$$

The imaginary $K^{I}$ part resulting only from the core layer (viscoelastic). For each eigenvalue, the ratio of the imaginary part to the real part is the loss factor and the square root of the real part represents the natural frequency:

$$
\Omega^{2}=\frac{K^{R}}{M}, \quad \eta=\frac{K^{I}}{K^{R}}
$$

This will explain the physical meaning of the real and imaginary parts of the modal stiffness constants. The introduction of an equivalent structural loss factor as a function of the amplitude makes it possible to characterize the dissipation capacity of the structure. From Eq. (16), the equation of motion for beam can be written in the form:

$$
[M]\{\ddot{q}\}+[C]\{\dot{q}\}+[K]\{q\}=\{F\},
$$

where: $[C]=\frac{[K]^{I}}{\omega}$ is the equivalent damping matrix and $\{F\}$ is the external nodal load vector, obtained by assembling the formulated element load vector, defined as:

$$
\{F\}=F_{0}\left\{\begin{array}{llllllll}
0 & \ldots & \underbrace{N_{w 1}^{N_{w 2}}}_{\text {element under loading }} & & N_{w 3} & N_{w 4} & 0
\end{array}\right\}^{T} .
$$

\section{Results and discussions}

In this study, a numerical code of finite elements is developed under MATLAB for dynamic analysis of sandwich beam with viscoelastic core under moving loads. The differential equation (20) is solved by using the implicit time integration Newmark method with parameters $\gamma=0.5$ and $\beta$ $=0.25$. The mobile load is $100 \mathrm{~N}$ moving at a constant speed of $10 \mathrm{~m} / \mathrm{s}$. The number of finite elements used in this code is equal to 100 . This code is used to calculate the frequencies, the loss factor, the dynamic responses due to the mobile load and the dynamic amplification factor. The model of viscoelastic behavior is considered with a module $E_{c}$ independent of the frequency given by:

$$
E_{c}=E_{0}\left(1+i \eta_{v}\right)
$$

where: $E_{0}$ is the real modulus and $\eta_{v}$ is the material loss factor do not depend on the frequency. This model is widely used to study viscoelastic behavior. In this paper, the Eq. (16) is solved iteratively for $\omega_{n}$, the resonant frequency for mode $n$, and $\eta_{n}$, the corresponding modal loss factor.

\subsection{Validation}

The real natural frequencies and loss factors of sandwich of the simply supported sandwich beam with viscoelastic core with aluminum face layers are calculated from Eq. (19) and compared with the corresponding results obtained by Billasse [10]. The mechanical properties of the viscoelastic sandwich beam with Aluminum face layers are given in Table 1.

Table 1

Mechanical properties of the the sandwich beam.

\begin{tabular}{|l|c|c|}
\hline & Elastic face & Viscoelastic core \\
\hline Young's module, $\mathrm{Pa}$ & $E_{f}=6.9 \mathrm{E} 10$ & $E_{0}=1749 E 3$ \\
\hline Poisson's ratio & $v_{f}=0.3$ & $v_{\mathrm{c}}=0.3$ \\
\hline Density, $\mathrm{kg} / \mathrm{m}^{3}$ & $\rho_{f}=2766$ & $\rho_{\mathrm{c}}=968.1$ \\
\hline Thickness, $\mathrm{m}$ & $h_{f}=1.524$ & $h_{\mathrm{c}}=0.127$ \\
\hline Length, Width, $\mathrm{m}$ & \multicolumn{2}{|c|}{$L=177.8, \quad b=12.7$} \\
\hline
\end{tabular}

The results are obtained for different values of viscoelastic core loss factor $\eta_{v}=0.1,0.6$ and 1.0. The real nat-

\begin{tabular}{|c|c|c|c|c|c|}
\hline \multirow[b]{2}{*}{$\eta_{v}$} & \multirow[b]{2}{*}{ Mode } & \multicolumn{2}{|c|}{ Present formulation } & \multicolumn{2}{|c|}{ Billasse [10] } \\
\hline & & $\Omega, \mathrm{Hz}$ & $\eta / \eta_{v}$ & $\Omega, \mathrm{Hz}$ & $\eta / \eta_{v}$ \\
\hline \multirow{3}{*}{0.1} & 1 & 148.41 & 0.3501 & 148.51 & 0.3502 \\
\hline & 2 & 488.27 & 0.1953 & 488.48 & 0.1958 \\
\hline & 3 & 1034.50 & 0.1067 & 1034.75 & 0.1071 \\
\hline \multirow{3}{*}{0.6} & 1 & 150.60 & 0.33283 & 150,71 & 0,3328 \\
\hline & 2 & 489.54 & 0.19388 & 489,76 & 0,1943 \\
\hline & 3 & 1035.20 & 0.10654 & 1035,44 & 0,1069 \\
\hline \multirow{3}{*}{1.0} & 1 & 154.30 & 0.3053 & 154.42 & 0.3052 \\
\hline & 2 & 491.83 & 0.1914 & 492.07 & 0.1918 \\
\hline & 3 & 1036.40 & 0.1062 & 1036.69 & 0.1065 \\
\hline
\end{tabular}
ural frequencies and loss factors corresponding to the first three modes sandwich beam are given in Table 2 . The results show that as the damping factor of the viscoelastic core increases, the damped pulsation also increases involving the improvement of the structural damping level.

Table 2

Real natural frequencies $\Omega$ and loss factor $\eta$ of the sandwich beam for different values of $\eta_{v}$. 
The obtained results are very acceptable, given their coincidences with those obtained by Billasse [10] that shows the effectiveness of the present approach.

\subsection{Vibrations analysis}

The effects of geometric parameter $(h / H)$ and viscoelastic loss factor on natural frequencies and structure loss factors are studied. First, we examine the effect of the sandwich beam configuration parameters such as viscoelastic loss factor and the ratio of thickness $h / H$ on the damping properties of the structure. The configuration and geometric properties of the sandwich beam considered are given in Fig. 1 and Table 3, respectively.

Table 3

Mechanical properties of the viscoelastic sandwich beam.

\begin{tabular}{|l|c|c|}
\hline & Layer face & Viscoelastic core \\
\hline Young's & $E_{1}=14.7 E 10$ & \\
modulus $(\mathrm{Pa})$ & $E_{2}=9.0 E 9$ & $E_{C}=7.037 \mathrm{E} 5\left(2\left(1+v_{\mathrm{c}}\right)\right)$ \\
\hline Poisson's ratio & $G=5.0 E 9$ & \\
\hline Density $\left(\mathrm{kg} / \mathrm{m}^{3}\right)$ & $v_{1}=0.3$ & $v_{c}=00.49$ \\
\hline Thickness $(\mathrm{m})$ & $\rho_{f}=H-h h_{2}=2 h H=0.012 h=0.0012$ \\
\hline
\end{tabular}

\subsubsection{Free vibrations}

The variations of the real natural frequencies and loss factors corresponding to the first three modes for different configuration parameters, viscoelastic loss factor and thickness ratio of the simply supported sandwich beam are reported in Fig. 3.

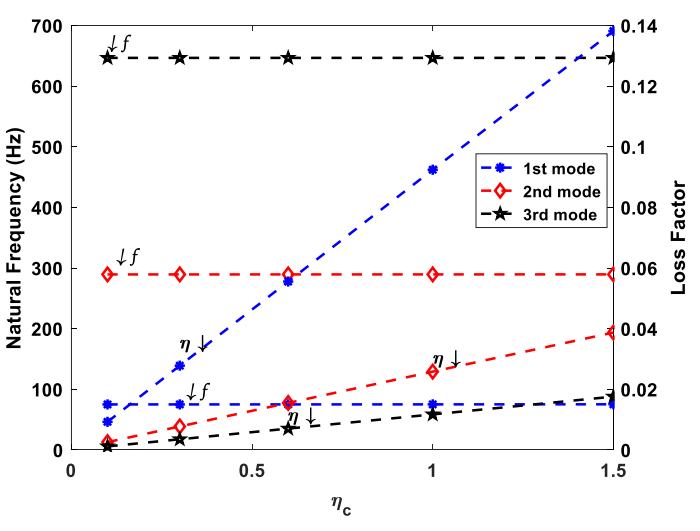

a

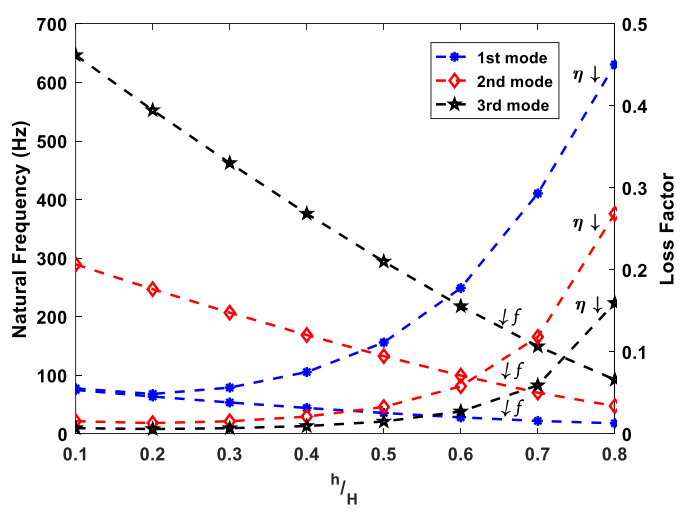

b

Fig. 3 Real naturel frequencies and loss factors of the sandwich beam according to the parameters: a) $\eta_{v}$; b) $h / H$
Proportional relationship between the viscoelastic loss factor and the structure loss factor shown in Fig. 3, a, nevertheless the eigen frequencies remain constant. The results are quite logical given the importance of the imaginary part of Young's modulus that reflects the ability of viscoelastic materials to dampen vibrations. Especially when this imaginary part is considerable, the results of Fig. 3, b, illustrate that the frequencies are inversely proportional to the thickness ratios $h / H$. This means that the frequencies decrease when the thickness ratio increases.

\subsubsection{Forced vibrations}

The time-forced responses of the sandwich beam are illustrated for different values of $\eta_{v}$. Fig. 4 show the responses dynamic obtained for different values of $\eta_{v}=0.1$, $0.6,1.0$ and 1.5 with $h H=0.1$ at velocity of moving load, $v$ $=10 \mathrm{~m} / \mathrm{s}$. It is observed that the effect of the viscoelastic loss factor is particularly significant for free oscillations whose amplitudes of oscillations are very small for the large values of $\eta_{v}$.

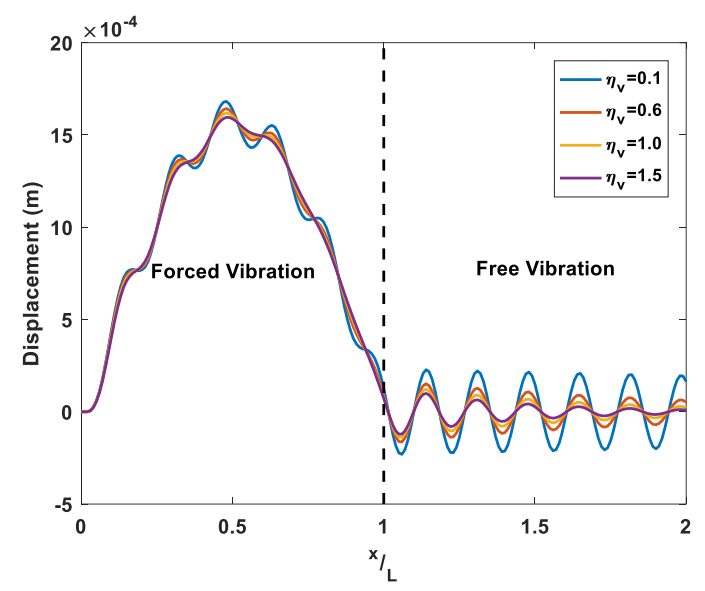

Fig. 4 Dynamic responses of the sandwich beam under moving load for different values of $\eta_{v}$

The dynamic amplification factor (DAF) responses for different values of $\eta_{v}$ are reported in Fig. 5. This factor is defined as the ratio between the maximum value of the dynamic displacement under moving load and the static displacement under concentrated force. The Fig. 5 show that the critical speeds vary from one configuration to another, for which $\eta_{v}=0.6, V_{c}=75,25,45$ and $25(\mathrm{~m} / \mathrm{s})$ respectively. The impact of the viscoelastic damping on the DAF is very considerable considering the decrease in the amplitudes of the DAF of the studied cases for with $h H=0.1$, after having increased the viscoelastic loss factor.

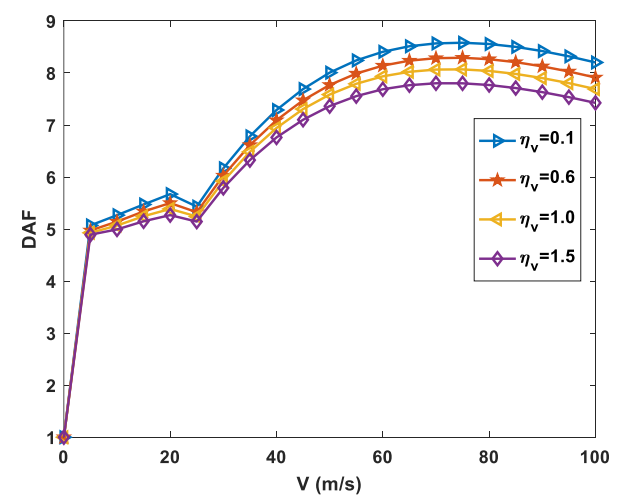

Fig. $5 \mathrm{DAF}$ of the sandwich beam for different values of $\eta_{v}$ 
The deflection responses of the sandwich beam with the effect of the thickness ratio are illustrated in Fig. 6 for different values of the viscoelastic loss factor $\eta_{\mathrm{v}}$ at $v=10 \mathrm{~m} / \mathrm{s}$. The results obtained from Figs. 6, a $-\mathrm{c}$ reveal that the amplitudes of the responses increase with the increase in the $h_{c}$ whose amplitudes with $\eta_{v}=0.6$ reach $w=1.6 \mathrm{e}-3,3.5 \mathrm{e}-3,15 \mathrm{e}-3$ and $46.4 \mathrm{e}-3(\mathrm{~m})$ for respectively $h H=0.1,0.3,0.6$ and 0.8 . However, the damping capacity becomes more significant for these values which have been noticed for the ratios $h / H=0.6$ and 0.8 whose free oscillations have disappeared more rapidly compared with those obtained with $h / H=0.1$ and 0.3 . The viscoelastic damping can be improved by increasing the thickness of the viscoelastic layer while keeping the thickness of the face layers.

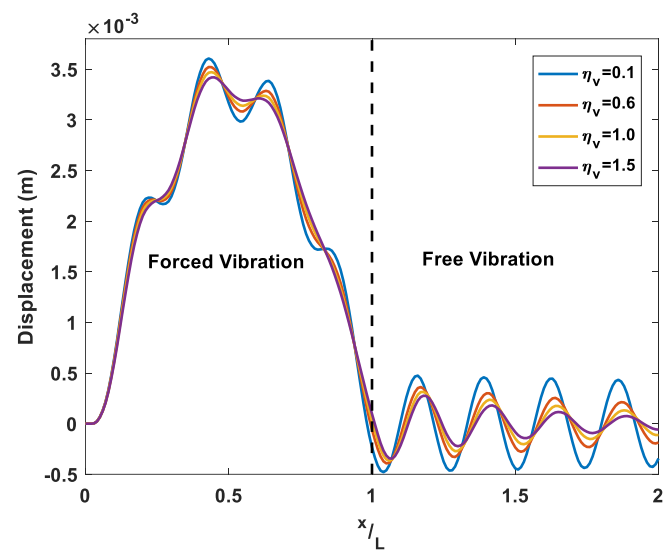

a

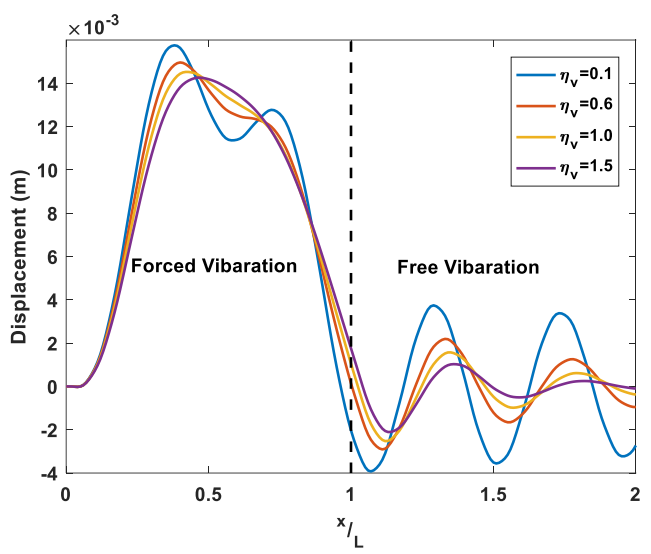

b

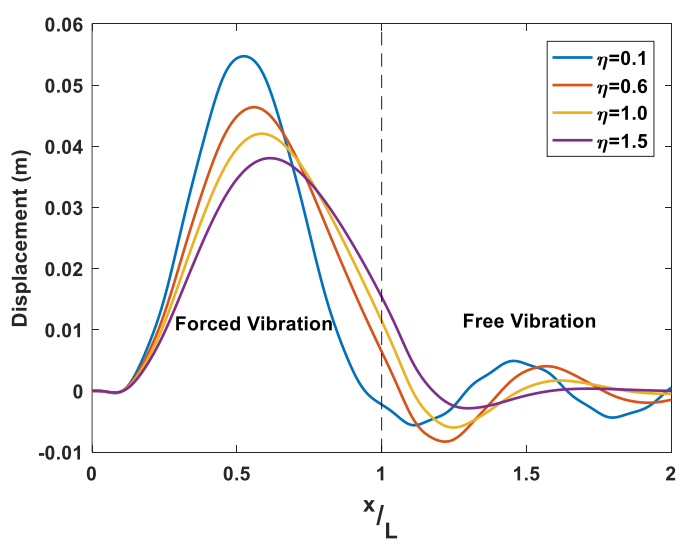

c

Fig. 6 Forced dynamic responses of the sandwich beam for different values of $\eta_{v}$ : a) $h / H=0.3$; b) $h / H=0.6$; c) $h / H=0.8$
The responses obtained from the DAF for different values of $\eta_{v}$ and $h H$ are presented in Fig. 7. The effect of the damping is also clear from what is illustrated in Figs. 7, ac especially in the hypercritical region where the effect of the viscoelastic damping becomes more significant.

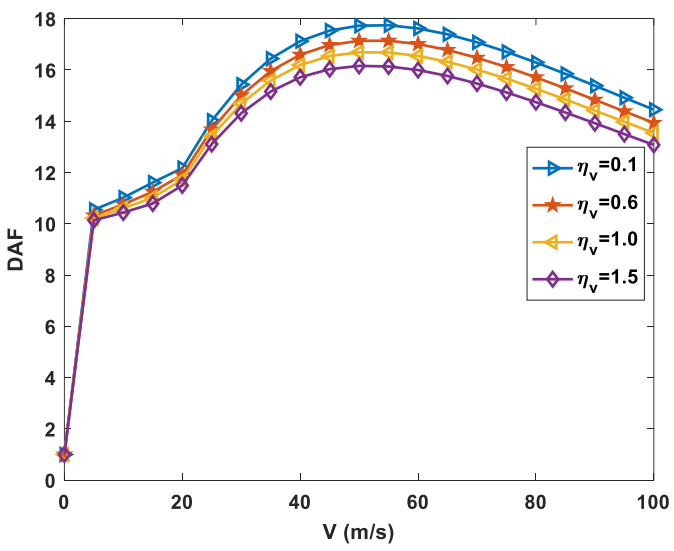

a

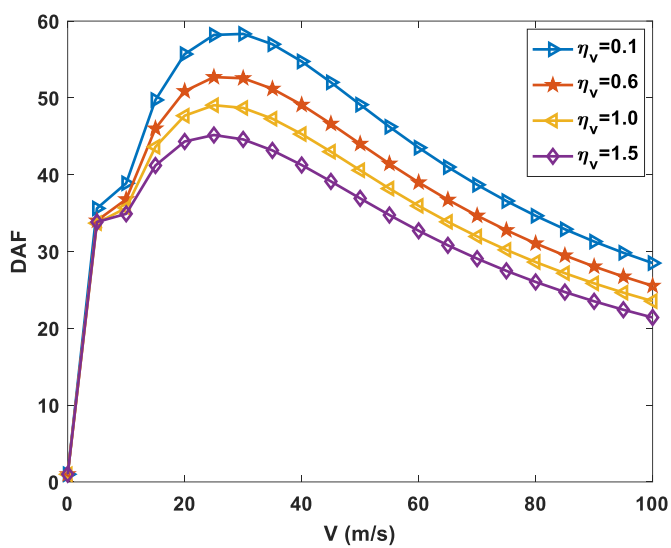

$\mathrm{b}$

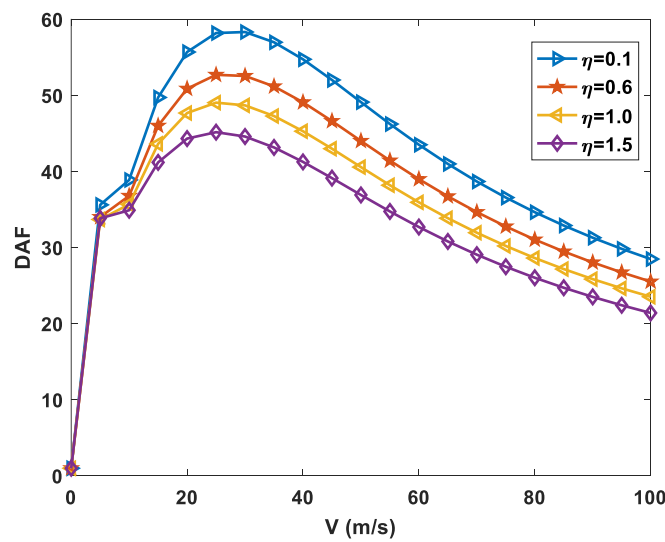

Fig. 7 DAF of the sandwich beam for different values of $\eta_{v}$ : a) $h / H=0.3$; b) $h / H=0.6$; c) $h / H=0.8$

\section{Conclusions}

The vibration behaviors of sandwich beams with viscoelastic core under moving force are investiged numerically. From the work done, several conclusions can be drawn: The significant effect of the loss factor of frequency-independent viscoelastic modulus on the dynamic behavior involving the improvement of the overall damping 
of the structure which consequently allows to reduce the amplitudes of vibrations when the factor becomes considerable. The maximum amplitudes of the vibratory responses of the sandwich beams are proportional to the thickness ratio $H / h$ between the viscoelastic layer and the face layer, the damping of which becomes very significant with a very thin thickness of the viscoelastic layer involving the decrease of the amplitudes of displacement. Thus, the damping of the structure becomes more significant as the thickness of the viscoelastic core layer becomes thinner. This amounts to the shear force applied to the viscoelastic layer for this type of configuration, which consequently makes it possible to further improve the damping provided essentially by the viscoelastic layer.

\section{Acknowledgements}

The authors gratefully acknowledge the Algerian General Direction of Research for providing the facilities and the financial funding of this project (A11-N01-UN2301-2019-0002).

\section{References}

1. Hilal, M. A.; Zibdeh, H. S. 2000. Vibration analysis of beams with general boundary conditions traversed by a moving force, J. Sound Vib. 229(2): 377-388. https://doi.org/10.1006/jsvi.1999.2491.

2. Giunta, F.; Muscolino, G.; Sofi, A.; Koff, I. E. 2017. Dynamic analysis of Bernoulli-Euler beams with interval uncertainties under moving loads, Procedia Eng. 199: 2591-2596. https://doi.org/10.1016/j.proeng.2017.09.353.

3. Chen, Y.; Fu, Y.; Zhong, J. et al. 2017. Nonlinear dynamic responses of fiber-metal laminated beam subjected to moving harmonic loads resting on tensionless elastic foundation, Compos. Part B Eng. 131: 253-259. https://doi.org/10.1016/j.compositesb.2017.07.051.

4. Tekili, S.; Khadri, Y.; Merzoug, B. 2015. Finite element analysis of free vibration of beams with composite coats, Mechanika 21(4): 290-295. https://doi.org/10.5755/j01.mech.21.4.9849.

5. Kiral, Z.; Kiral, B. G. 2008. Dynamic analysis of a symmetric laminated composite beam subjected to a moving load with constant velocity, J. Reinf. Plast. Compos 27(1): 19-32. https://doi.org/10.1177/0731684407079492.

6. Fuh-Gwo, Y.; Miller, R. E. 1989. A new finite element for laminated composite beams, Comput. Struct. 31(5):737-745. https://doi.org/10.1016/0045-7949(89)90207-1.

7. Kahya, V. 2012. Finite element dynamic analysis of laminated composite beams under moving loads, Structural Engineering \& Mechanics 42(4):729-745. https://doi.org/10.12989/sem.2012.42.5.729.

8. Sarvestan, V.; Mirdamadi, H. R.; Ghayour, M. 2017. Vibration analysis of cracked Timoshenko beam under moving load with constant velocity and acceleration by spectral finite element method, Int. J. Mech. Sci, 122: $318-330$. https://doi.org/10.1016/j.ijmecsci.2017.01.035.

9. Irazu, L.; Elejabarrieta, M. J. 2017. The effect of the viscoelastic film and metallic skin on the dynamic properties of thin sandwich structures, Comput. Struct. 176: $407-419$. https://doi.org/10.1016/j.compstruct.2017.05.038.

10. Bilasse, M.; Daya, E. M.; Azrar, L. 2010. Linear and nonlinear vibrations analysis of viscoelastic sandwich beams, J. Sound Vib. 329 (23): 4950-4969. https://doi.org/10.1016/j.jsv.2010.06.012.

11. Meirovitch, L. 1997. Principles and techniques of vibrations, 1st ed. Prentice Hall.

12. Clough, R. W.; Penzien, J. 1993. Dynamics of structures, McGraw-Hill, New York, USA.

13. Daya, E. M.; Azrar, L.; Potier-Ferry, M. 2004. An amplitude equation for the non-linear vibration of viscoelastically damped sandwich beams, Journal of Sound and Vibration 271:789-813. https://doi.org/10.1016/S0022-460X(03)00754-5.

\section{S. Tekili, Y. Khadri, Y. Karmi}

\section{DYNAMIC ANALYSIS OF SANDWICH BEAM WITH VISCOELASTIC CORE UNDER MOVING LOAD}

S u m m a r y

In this article, numerical approach is proposed for dynamic behavior of symmetrical sandwich beams with viscoelastic core under moving load using the Hamilton's principle formulation and the finite element method solution. The dynamic responses are obtained for different configurations using the modal superposition method and the implicit Newmark integration scheme. The analysis shows that the viscoelastic damping has a significant effect on the vibration behavior involving the improvement of the damping of the structure. The parametric study of the effect of the configuration parameters shows that the sandwich structure has more dissipative capacities of vibratory energy by adopting adequate configurations to the structure.

Keywords: vibration, sandwich, viscoélastic material, damping, moving load.

Received: September 26, 2019 Accepted: August 24, 2020 